\title{
Application of Electrochemical Methods for Analysis of Fluoroquinolones Antibacterial Agents and Fluoroquinolones-DNA Interactions
}

\author{
Abd-Elgawad Radi* \\ Department of Chemistry, Faculty of Science (Dumyat), Mansoura University, 34517 Dumyat, Egypt
}

\begin{abstract}
This mini review describes the results regarding the voltammetric determination of micromolar, submicromolar and nanomolar concentrations of various fluoroquinolones antibacterial agents using both traditional hanging mercury drop electrode, carbon paste electrode, glassy carbon paste electrode and chemically modified electrodes. We concentrate on the interaction of quinolones with DNA in solution and at electrode surface in the context of the general development in the field.
\end{abstract}

Keywords: Electrochemical methods, fluoroquinolones, DNA interaction, voltammetry.

\section{INTRODUCTION: QUINOLONES HISTORY AND STRUCTURE}

The term quinolones is commonly used for the quinolone carboxylic acids or 4-quinolones; a group of synthetic antibacterial agents containing 4-oxo-1,4-dihydroquinoline skeleton. The first analogue of this class, nalidixic acid, was synthesized in 1962 [1] and used for the treatment of urinary tract infections [2]. It is more active against Gram-positive than Gram-negative organisms $[3,4]$. The major metabolite of nalidixic acid is similar in spectrum and potency to that of the parent compound $[5,6]$. The molecular structures of the quinolones have been adapted over time in association with clinical need. The addition of chemical groups to the original quinolone nucleus has allowed the development of different levels of increasing quinolone bacterial activity [7]. Antimicrobial activity of the first-generation fluoroquinolones (nalidixic acid) is high against aerobic Gram-negative bacteria including most enterobacteria; however, the activity against aerobic Gram-positive bacteria is poor [8]. Second generation fluoroquinolones (norfloxacin, ciprofloxacin, ofloxacin and levofloxacin) show improved activity against Gram-negative bacteria, including excellent activity against Pseudomonas aureginosa (particularly in the case of ciprofloxacin) and added activity against aerobic Grampositive bacteria with poor activity against anaerobic pathogens $[9,10]$. The addition of third generation fluoroquinolones (grepafloxacin, sparfloxacin, temafloxacin, tosufloxacin, pazufloxacin) added activity against anaerobes and greater potency against aerobic Gram-positive bacteria, particularly against Streptococcus pneumoniae, and the newer fourth generation fluoroquinolones (gatifloxacin, trovafloxacin, gemifloxacin, moxifloxacin) show potent activity against anaerobes and an impressive activity against Streptococcus pneumoniae, including penicillin and cephalosporin resistant isolates [11-14].

*Address correspondence to this author at the Department of Chemistry, Faculty of Science (Dumyat), Mansoura University, 34517 Dumyat, Egypt; Tel: +20-57-2403866; Fax: +20-57-2403868; E-mail: abdradi@yahoo.com

\section{MECHANISM OF ACTION OF FLUORO- QUINOLONES}

The bactericidal activity generated by fluoroquinolones is caused by their inhibition of two bacterial enzymes: DNA gyrase and topoisomerase IV enzymes. DNA gyrase (topoisomerase II) is an essential enzyme involved in the replication, transcription and reparation of the bacterial DNA. This enzyme is composed of a tetramer of two subunits: GyrA and GyrB. The A subunit is responsible for breakage and resealing of chromosomal DNA. The B subunit is responsible for energy transduction from ATP hydrolysis. Topoisomerase IV is an enzyme responsible for the separation of daughter DNA strands during bacterial cell division in Gram-positive bacteria and it is composed of a tetramer of two subunits: ParC and ParE. In Gram negative organisms DNA gyrase is the primary target, in the case of topoisomerase IV the Gram-positive bacteria is the most affected. Currently several structural models have been suggested to account for the action of quinolones [15-23]. In common, all suggested models require a direct interaction between the drug and either single or double-stranded DNA [24]. One of these models suggests that $\mathrm{Mg}^{2+}$ plays an important role in the drug binding to a DNA-gyrase complex [25-28]. However the exact mechanism of action is still unclear and several points such as: (i) preference for singleor double-strand DNA binding; (ii) the role of $\mathrm{Mg}^{2+}$ ions; (iii) groove binding versus classical interaction need to be addressed. Thus, contribution to deeper insight into the mechanism of interaction of this class of antibiotics with DNA is important for a better understanding of their therapeutic efficiency.

\section{ELECTROCHEMICAL REDUCTION OF FLUORO- QUINOLONES ON MERCURY ELECTRODE}

A great number of papers have been reported for the determination of fluoroquinolones in pharmaceutical formulations and biological samples [29]. Electrochemical methods have proved to be sensitive and reliable for the determination of numerous electroactive drug components [30-32]. They are useful both for the analysis of 
pharmaceutical dosage forms and determination of drugs in biological fluids. The presence of carbonyl and carboxylic acid groups within the fluoroquinolones molecules has initiated several polarographic studies. Electrochemical stripping techniques proved highly suitable tools for fluoroquinolones analysis. Strong tendency of fluoroquinolones to accumulate on the electrode surface offers a possibility of their highly sensitive determination by stripping voltammetry.

The direct current polarographic reduction and preparative electrolysis of nalidixic acid at the DME was first reported by Starosak et al. [33]. The limit of quantification of this method $\left(10^{-5}-10^{-6} \mathrm{M}\right)$ was high. VanOort et al. determined the total content of nalidixic acid and its metabolite, the 7-hydroxymethyl derivative, using the polarographic reduction on the dropping mercury electrode [34]. A differential pulse polarographic method was applied to urine samples, after extraction into chloroform using direct current and differential pulse polarographic signals.

The nalidixic acid drug was studied by cyclic voltammetry and cathodic adsorptive stripping voltammetry [35]. A sensitive method was described for the determination of the drug in its pure form, dosage forms and biological fluids. Controlled adsorptive accumulation of nalidixic acid on a hanging mercury drop electrode provides the basis for the direct stripping measurement of that compound at a nanomolar concentration level. Cathodic adsorptive stripping voltammetry has been proved to be advantageous over a liquid chromatographic technique, allowing lower detection limit of nalidixic acid to be reached. The method was applied for two different commercial pharmaceutical products (tablets and suspension) with very good recoveries. It was also shown that the method was successfully applied to the determination of nalidixic acid in human urine and blood serum.

Nalidixic acid and its main metabolite, 7hydroximethylnalidixic acid showed an adsorption process on a hanging mercury electrode [36]. On this basis, a square wave adsorptive stripping voltammetry method has been developed for the individual and simultaneous determination of the drug and its main metabolite. The method was applied to urine samples containing only one of the analytes with satisfactory recoveries. As the voltammetric signals of these compounds show a high overlapping, different chemometric methods have been used for the resolution of the mixture. The analysis of these compounds in urine samples were carried out using the different chemometric tools and with good recoveries. No pre-treatment of the sample was necessary, only dilution was enough.

A sensitive method was described for the determination of ofloxacin in its pure form, dosage forms and biological fluids [37]. The proposed method based on the polarographic activity of ofloxacin in Britton Robinson buffers, whereby a well-defined cathodic wave was produced. The wave was characterized as being irreversible, diffusion-controlled with limited adsorption properties. The proposed method was successfully applied to the determination of ofloxacin in tablets and biological fluids. The results obtained were found to be in agreement with that obtained by a reference method.
The polarographic and voltammetric behaviour of enoxacin was described. There was a well defined reductive peak using linear sweep voltammetry in $\mathrm{H}_{2} \mathrm{SO}_{4}$ solution [38]. The peak current was proportional to the concentration of enoxacin. The characteristics of the peak were examined in detail. The results proved that the reduction of enoxacin was irreversible and the peak had adsorption characteristics. A mechanism was proposed for the reduction of enoxacin.

Flumequine was found to be reduced at the dropping mercury electrode in Britton-Robinson buffer containing methanol as a solubilizer [39]. A well-defined cathodic wave was produced over this entire range. The wave was characterized as being diffusion-controlled, although adsorption phenomena played a limited role in the reduction process. The proposed method was applied to the determination of flumequine in tablets, and the results were satisfactorily accurate and precise.

Linear sweep votammetry [40] and differential pulse polarography [41] were used to study quinolone antibiotics: ciprofloxacin, enoxacin, norfloxacin, ofloxacin and pefloxacin on a mercuty electrode. The optimal parameters and background solutions have been chosen. New voltammetric method for quinolone determination in pure from and pharmaceutical formulations was found. Statistical analysis of the results obtained showed that the proposed method was of good accuracy and precision.

Sensitive cathodic stripping voltammetric methods have been developed for two quinolone antibacterial drugs, pipemidic acid and ofloxacin using hanging mercury drop electrode [42]. The methods were developed for the determination of drugs individually as well as simultaneously. The presence of glucose, lactose, sorbitol, gum arabic, starch, magnesium stearate, methylparaben and propylparaben did not affect the determinations of both pipemidic acid and ofloxacin. The methods were used for the analysis of pharmaceutical preparations. Pipemidic acid and ofloxacin could also be determined simultaneously, and were determined in spiked human urine.

A linear sweep stripping voltammetric method has been developed for simultaneous quantitative determination of mixtures of three antibiotic drugs, ofloxacin, norfloxacin and ciprofloxacin [43]. It relied on the reductive reaction of the antibiotics at a mercury electrode in a Britton-Robinson buffer. The voltammograms of these three compounds overlapped strongly, and showed non-linear character. Thus, it was difficult to analyse the compounds individually in their mixtures. The chemometrics methods were applied for the simultaneous determination of these compounds. The proposed analytical method based on linear sweep stripping voltammetry was applied for the analysis of ofloxacin, norfloxacin and ciprofloxacin antibiotics in bird feedstuffs and their spiked samples, as well as in eye drops with satisfactory results.

Direct current polarography and cyclic voltammetry were used to study quinolone antibiotics: ciprofloxacin, enoxacin, norfloxacin, ofloxacin and pefloxacin on mercury and carbon electrodes [44]. The dependence of limiting currents and half-wave potentials on the $\mathrm{pH}$ of the solution, mercury head, temperature, ionic strength of the solution, methyl cellulose concentration, scan rate and quinolone 
concentration was studied. The optimal parameters and background solutions have been chosen. It was concluded that on mercury electrode quinolones are reduced in two oneelectron waves and the process of the reduction was accompanied by an acid-base equilibrium. An anodic peak observed on graphite electrode was probably caused by the oxidation of piperazine ring in the molecule.

A sensitive reduction wave of norfloxacin was obtained by single-sweep oscillopolarography in $\mathrm{NH}_{4} \mathrm{Cl}$ solution [45]. The adsorptive characteristics of the system have been studied by means of linear sweep; cyclic voltammetry and normal pulse polarography. The electrode reduction process was irreversible with adsorptive characteristics. The method has been applied to the determination of norfloxacin.

Cyclic voltammetric investigations have been performed which showed that norfloxacin exhibited adsorptive processes at the hanging mercury drop electrode in various base electrolytes [46]. The optimum experimental parameters were assessed for each base electrolyte. Calibration plots covered ultratrace levels of norfloxacin depending on the base electrolyte and the adsorptive peak used for analysis. These linearities may be ascribed to pure adsorptive and mixed adsorptive-diffusion processes. Norfloxacin in Noroxin commercial tablets was determined using the standard addition technique. Good recoveries were obtained without an interference from the drug excipients.

The polarographic and voltammetric behavior of ciprofloxacin lactate and its application were studied. A well-defined reduction peak was yielded by ciprofloxacin in $\mathrm{NH}_{4} \mathrm{Cl}-\mathrm{NHOH}$ buffer solution [47]. The experimental results showed that the reduction of ciprofloxacin belong to an irreversible process with reactant adsorption. The electrode reaction mechanism was preliminarily presented. Most of metallic ions did not interfere with the determination. This behavior was used to determine ciprofloxacin in raw samples and injections and could also be used to determine the trace ciprofloxacin in serum, plasma and urine samples. It might provide a simple, rapid and sensitive method for determination in clinical medicine and pharmacokinetics.

A simple, rapid, reliable and fully validated square wave cathodic adsorptive stripping voltammetric procedure has been developed for the determination of the pefloxacin drug in bulk form, tablets and human serum, based on its electrochemical reduction at a hanging mercury drop electrode [48]. At the optimized conditions, a single 2electron well-defined peak attributed to the reduction of the $\mathrm{C}=\mathrm{O}$ group was obtained. The proposed procedure was successfully applied for the determination of the drug in tablets and human serum. The results of the proposed procedure were comparable with those obtained by reported methods.

The voltammetric behaviour of enrofloxacin, sparfloxacin and fleroxacin was studied using direct current, differential pulse and alternating current polarography [49]. All the drugs manifested cathodic waves which were characterized as being irreversible, diffusion-controlled with limited adsorption properties. The proposed method was successfully applied for the determination of the studied compounds either per se or in formulations and biological fluids. The results obtained were concordant to those given using reference methods.

An electroanalytical methodology was developed for square-wave voltammetry based on the electrochemical reduction on hanging mercury drop electrode, which was simple, fast, reliable and sensitive for determination of moxifloxacin in tablets and spiked urine human samples [50]. At the best-optimized conditions the drug presented a single peak of reduction. A good recovery was obtained for the assay of spiked urine samples and a good quantification of moxifloxacin was achieved in a commercial formulation. The methodology proposed was more sensitive than the spectrofluorimetric and spectrophotometric method with equivalent recision and accuracy.

A simple, fast, sensitive and fully validated differential pulse polarographic method for the determination of trace amounts of moxifloxacin in pharmaceutics, serum and urine was reported [51]. Moxifloxacin exhibited a well-defined irreversible cathodic peak in Britton-Robinson buffer. The current has been characterized as being diffusion-controlled process. The proposed method was applied to commercial tablets and average percentage recovery was in agreement with that obtained by spectrophotometric comparison method. The method was extended to the in vitro determination of moxifloxacin in spiked human serum and urine.

The direct current and differential pulse polarographic reduction of fleroxacin was done in a wide $\mathrm{pH}$ range [52]. The appropriate buffer choice was made for its polarographic determination. The adsorptive properties of fleroxacin were investigated in order to achieve an increase in sensitivity and a possibility of fleroxacin determination by applying the adsorptive stripping voltammetric method. The adsorptive processes at the hanging mercury drop electrode were investigated in Britton-Robinson and borate buffers. Adsorptive preconcentration followed by differential-pulse cathodic stripping showed one wave which was sensitive for analytical determination of fleroxacin.

\section{ELECTROCHEMISTRY OF THE METAL IONS- FLUOROQUINOLONE COMPLEXES}

The interaction of biologically active metal ions: $\mathrm{Co}(\mathrm{II})$, $\mathrm{Cr}(\mathrm{JII}), \mathrm{Fe}(\mathrm{III}), \mathrm{Mn}(\mathrm{II})$ and $\mathrm{Cu}(\mathrm{II})$ with norfloxacin has been studied at platinum working electrode using cyclic voltammetric technique [53]. The voltammetric pattern showed characteristic peaks with norfloxacin, however, the peaks of the free metal ions were influenced by the presence of norfloxacin indicating complexation with the metal ions. The results showed that norfloxacin formed complexes with metal ions in 1:2 ratio. The values of stability constant and thermodynamic parameters $\Delta \mathrm{G}^{\circ}, \Delta \mathrm{H}^{\circ}$ and $\Delta \mathrm{S}^{\circ}$ for complex formation are evaluated. These findings reveal the possible use of various metal ions for analytical and chemotherapeutic investigations with norfloxacin.

Sparfloxacin and its pharmaceutical formulation have been analysed using polarographic and amperometric methods [54]. Complexation behavior of sparfloxacin with $\mathrm{Fe}(\mathrm{II})$, both in solid and liquid phases has been studied by elemental analysis, IR-spectra and polarographic and amperometric methods. Sparfloxacin produced a single cathodic reduction. The wave was diffusion controlled and 
wave height was proportional to the concentration of sparfloxacin. The complex was also reversibly reduced at the electrode surface with diffusion-controlled kinetics. The stoichiometry of the Fe(II)-sparfloxacin complex was 1:1. Antibacterial studies on the drug and its metal complex have been performed against different bacteria. The observed results revealed the complex to be more potent in its antibacterial activity as compared to the parent drug. On the basis of observed results it could be concluded that the prepared Fe(II)-sparfloxacin complex may be recommended to the therapeutic experts for its possible use as a more potent antibiotic drug.

Two simple, precise, inexpensive and sensitive voltammetric methods for the determination of lomefloxacin, sparfloxacin hydrochloride, gatifloxacin, and moxifloxacin were developed [55]. The present methods were first used to explore the adsorption behavior of the four investigated antibacterial agents at a hanging mercury dropping electrode, by a direct method and secondly by a modification via their complexation with $\mathrm{PdCl}_{2}$. For the direct method, the adsorptive stripping response was evaluated as a function of some variables such as the scan rate, $\mathrm{pH}$, accumulation time and potential. For the modified method, the adsorptive behavior of $\mathrm{Pd}(\mathrm{II})$-4-quinolone complexes at the hanging mercury dropping electrode developed a strippining voltammetry peak at a more negative potential than that of the free $\mathrm{Pd}(\mathrm{II})$ ions. The methods were applied to the determination of lomefloxacin, sparfloxacin hydrochloride, gatifloxacin, and moxifloxacin in biological samples and pharmaceutical preparations, and also compared with the official reference methods. Complete validation of the proposed methods was also done.

An electroanalytical method for the determination of moxifloxacin in tablets by its interaction with $\mathrm{Cu}(\mathrm{II})$ ion and subsequent electrochemical reduction at hanging mercury drop electrode has been developed [56]. A well-defined reduction peak in phosphate buffer was observed using accumulation for the complex moxifloxacin- $\mathrm{Cu}(\mathrm{II})$, using square-wave voltammetry. The obtained results have shown good agreement with those obtained by spectrophotometric method.

The polarographic reduction of $\mathrm{Co}$ (II) in the presence of moxifloxacin gave rise to an additional adsorption peak corresponding to the reduction of $\mathrm{Co}(\mathrm{II})$-moxifloxacin complex on the mercury drop electrode [57]. This new peak was applicable to $\mathrm{Co}$ (II) determination and could be attributed to an adsorption-controlled process with an irreversible reduction. The accuracy of the method was also checked by the determination of $\mathrm{Co}$ (II) spiked with tap water and certified sea water, and excellent percentage recoveries were obtained.

A sensitive method for determination of trace zinc based on adsorptive preconcentration of zinc-nalidixic acid complex onto the surface of a hanging mercury drop electrode has been described [58]. The effect of positively and negatively charged ions on the peak height of $\mathrm{Zn}$ nalidixic acid complex was evaluated. The method was applied to the determination of zinc in: spring water, tap water, seawater, dry tea, Tab. Sanatogen gold A-Z, and NIST certified reference material with satisfactory results.
A simple and sensitive electroanalytical method was developed for the determination of enrofloxacin by adsorptive cathodic stripping voltammetry using $\mathrm{Cu}$ (II) as a suitable probe [59]. The complex of copper(II) with enrofloxacin was accumulated at the surface of a hanging mercury drop electrode. Then, the preconcentrated complex was reduced and the peak current was measured using square wave voltammetry. The optimization of experimental variables was conducted by experimental design and support vector machine modeling. The model was used to find optimized values for the factors such as $\mathrm{pH}, \mathrm{Cu}(\mathrm{II})$ concentration and accumulation potential. The influence of potential interfering substances on the determination of enrofloxacin was examined. The method was successfully applied to determination of enrofloxacin in plasma and pharmaceutical samples.

\section{ELECTROCHEMISTRY OF FLUOROQUINO- LONES AT SOLID ELECTRODES}

Pipemidic acid was determined by concentrating it on carbon fiber indicator electrode at $100 \mathrm{mV}$ for $30 \mathrm{~s}$ and applying anodic stripping voltammetry between 0 and $1.3 \mathrm{~V}$ [60]. The method was not affected by oxygen, no extraction was required before the voltammetric analysis, and the excipients present in the pipemidic tablets showed no interference with the analysis. The method was used for the determination of pipemidic in tablets with satisfactory results.

A detailed study of the electrochemistry of sparfloxacin at a glassy carbon electrode was carried out in aqueous solution using cyclic and differential pulse voltammetry [61]. The influence of different supporting electrolytes, $\mathrm{pH}$, scan rate and concentrations on the voltammetric response was studied. The studies revealed the irreversible oxidation of sparfloxacin at basic $\mathrm{pH}$ in a diffusion controlled manner. In addition, a differential pulse voltammetric method was proposed for the determination of the drug in different pharmaceutical formulations.

The adsorptive and electrochemical behavior of norfloxacin on a glassy carbon electrode was investigated by cyclic and square-wave voltammetry [62]. Cyclic voltammetric studies indicated that the process was irreversible and fundamentally controlled by adsorption. To obtain a good sensitivity, the solution conditions and instrumental parameters were studied using square-wave voltammetry. Norfloxacin gave a sensitive adsorptive oxidative peak in acetate buffer solution. Applicability to measurement of norfloxacin at submicromolar levels in urine samples was illustrated.

The electrochemical behaviors of norfloxacin on a pretreated glassy carbon electrode were investigated by cyclic voltammetry [63]. The results indicated that the process was irreversible and fundamentally controlled by adsorption. The solution conditions and instrumental parameters were investigated and optimized. This method was used for determination of norfloxacin in capsule. Chromatography analysis was also carried out to confirm this method. Statistical analysis of the results using Student t-test and the variance ratio F-test showed no significant difference between the performance of the two methods as regards to accuracy and precision. 
The anodic behavior and determination of pefloxacin on boron-doped diamond and glassy carbon electrodes were investigated using cyclic, linear sweep, differential pulse and square wave voltammetric techniques [64]. In cyclic voltammetry, pefloxacin showed one main irreversible oxidation peak and additional one irreversible ill-defined wave depending on $\mathrm{pH}$ values for both electrodes. The results indicated that the process of pefloxacin was irreversible and diffusion controlled on boron-doped diamond electrode and irreversible but adsorption controlled on glassy carbon electrode. The repeatability, reproducibility, precision and accuracy of the methods in all media were investigated. Selectivity, precision and accuracy of the developed methods were also checked by recovery studies. The procedures were successfully applied to the determination of the drug in pharmaceutical dosage forms and humans serum samples with good recovery results. No electroactive interferences from the excipients and endogenous substances were found in the pharmaceutical dosage forms and biological samples, respectively.

An electrochemical method was developed for the determination of ciprofloxacin based on the enhancement effect of cetyltrimethylammonium bromide (CTAB) [65]. A poorly-defined oxidation peak was observed at carbon paste electrode for ciprofloxacin in phosphate buffer solution. However, the oxidation peak current remarkably increased in the presence of low concentration of $\mathrm{CTAB}$, suggesting that CTAB exhibited obvious enhancement effect to the determination of ciprofloxacin. All the experimental parameters, such as supporting electrolyte, $\mathrm{pH}$ value, concentration of CTAB, and accumulation time, were optimized for ciprofloxacin analysis. This new method possessed high sensitivity, wide linearity, rapid response, low cost and simplicity. Finally, this method was successfully employed to detect ciprofloxacin in drugs.

The adsorption behavior of levofloxacin on a glassy carbon electrode was explored by cyclic and square-wave voltammetry [66]. The drug was accumulated on a glassy carbon electrode and a well-defined oxidation peak was obtained in acetate buffer $\mathrm{pH}$ 5.0. The square-wave anodic stripping voltammetric method was applied for the direct determination of levofloxacin in diluted urine samples. It was validated using high-performance liquid chromatography as a reference method.

Square-wave and cyclic voltammetric behaviour of solid microparticles of 5-aminosalicylic acid, ciprofloxacin, and azithromycin, mechanically immobilized on the surface of the paraffin impregnated graphite electrode, were investigated in order to develop a method for their qualitative determination [67]. 5-Aminosalicylic acid was oxidized at $0.540 \mathrm{~V}$ in the quasireversible electrode reaction, which was followed by the chemical transformation of the product, while ciprofloxacin and azithromycin were oxidized at $1.2 \mathrm{~V}$ and $0.94 \mathrm{~V}$, respectively, in totally irreversible electrode reactions. The detection of these drugs in commercial dosage formulations was reported.

Cyclic voltammetry and differential pulse voltammetry were used to explore the adsorption behavior of three antibacterial agents lomefloxacin, sparfloxacin hydrochloride, and gatifloxacin at a carbon paste electrode [68]. The drugs were accumulated on a carbon paste electrode, and a well-defined oxidation peak was obtained in acetate buffer. The adsorptive stripping response was evaluated as a function of some variables such as the scan rate, $\mathrm{pH}$ and accumulation time. A simple, precise, inexpensive and sensitive voltammetric method has been developed for the determination of the cited drugs. The method was applied to the determination of lomefloxacin, sparfloxacin hydrochloride, and gatifloxacin in dilute urine samples and dosage forms, and compared with the high-performance liquid chromatography method.

The oxidative behaviour of moxifloxacin was studied at a glassy carbon electrode in different buffer systems using cyclic, differential pulse, and Osteryoung square-wave voltammetry [69]. The oxidation process was shown to be irreversible over the entire $\mathrm{pH}$ range studied and was diffusion-controlled. The methods were performed in Britton-Robinson buffer and the corresponding calibration graphs were constructed the statistical data were evaluated. Applicability to tablets and human plasma analysis was illustrated. Furthermore, a high-performance liquid chromatographic method with diode-array detection was developed. The described methods were successfully employed with high precision and accuracy for estimation of the total drug content of human plasma and for pharmaceutical dosage forms of moxifloxacin.

\section{ELECTROCHEMISTRY OF FLUOROQUINO- LONES AT MODIFIED ELECTRODES}

The electrochemical behavior of ofloxacin, norfloxacin, gatifloxacin, and lomefloxacin [70] and similarly sparfloxacin [71] at $\beta$-cyclodextrin modified carbon paste electrodes has been described. A large increase in the peak currents was observed in cyclic voltammetry and differential pulse voltammetry of ofloxacin, norfloxacin, gatifloxacin, and lomefloxacin at $\beta$-cyclodextrin-modified carbon-paste electrode as compared with a bare carbon-paste electrode. These increases in the peak currents were attributed to the complex formation of the quinone group of the drugs with $\beta$ cyclodextrin. Cyclic voltammetric studies indicated that the process was irreversible and adsorption-controlled. The experimental parameters which influenced the peak current responses of ofloxacin, norfloxacin, gatifloxacin, and lomefloxacin were studied. The interference of metal ions in the peak current response was also studied. The modified electrode exhibited good sensitivity and stability. The proposed method was applied to the determination of ofloxacin, norfloxacin, gatifloxacin, and lomefloxacin in both commercially available drugs and spiked human urine samples.

A simple and rapid electrochemical method was developed for the determination of trace-level norfloxacin, based on the excellent properties of multi-walled carbon nanotubes (MWCNTs) [72]. The MWCNTs/Nafion film-coated glassy carbon electrode was constructed and the electrochemical behavior of norfloxacin at the electrode was investigated in detail. The results indicated that MWCNTs modified glassy carbon electrode exhibited efficiently electrocatalytic oxidation for norfloxacin with relatively high sensitivity, stability and life time. Under conditions of cyclic voltammetry, the current for oxidation of selected analyte is enhanced significantly in comparison to the bare GCE. The 
electrocatalytic behavior was further exploited as a sensitive detection scheme for the analyte determinations by linear sweep voltammetry. Under optimized condition in voltammetric method, the proposed method was successfully applied to norfloxacin determination in tablets. The analytical performance of this sensor has been evaluated for detection of the analyte in urine as a real sample.

A poly(methyl red) film-modified glassy carbon electrode was fabricated for the determination of norfloxacin [73]. The electrochemical behavior of norfloxacin was investigated and a well-defined oxidation peak with high sensitivity was observed at the film electrode. The poly(methyl red) film-modified glassy carbon electrode greatly enhanced the oxidation peak current of norfloxacin owing to the extraordinary properties of poly(methyl red) film. Based on this, a sensitive and simple voltammetric method was developed for measurement of norfloxacin. A sensitive linear voltammetric response for norfloxacin was obtained, using linear sweep voltammetry. The proposed method possessed advantages such as low detection limit, fast response, low cost and simplicity. The practical application of this new analytical method was demonstrated with norfloxacin pharmaceuticals.

Multiwalled carbon nanotubes-polymeric alizarin film modified electrode was made. The electrochemical behavior of levofloxacin hydrochloride on modified electrode was studied with cyclic voltammetry, linear sweep voltammetry and chronopotentiometry [74]. The results indicated that the electrical oxidation of levofloxacin hydrochloride on the modified electrode in HAc-NaAc buffer solution was irreversible and was controlled by diffusion. Some important parameters of the electrochemical process were evaluated. The recovery of levofloxacin hydrochloride in levofloxacin hydrochloride injection was satisfactory.

A labeless immunosensor for ciprofloxacin in milk and its interrogation using an ac impedance protocol was described [75]. Commercial screen-printed carbon electrodes were used as the basis for the sensor. Polyaniline was electrodeposited onto the sensors and then utilized to immobilize a biotinylated antibody for ciprofloxacin using classical avidin-biotin interactions. Antibody loaded electrodes were exposed to solutions of antigen in milk and interrogated using an ac impedance protocol. The faradaic component of the impedance of the electrodes was found to increase with increasing concentration of antigen. Control samples containing a nonspecific $\operatorname{IgG}$ antibody were also studied but were found to display large nonspecific responses, probably due to the antibody binding some of the large number of components found in milk. Control sensors could, however, be fabricated using antibodies specific for species not found in milk. Calibration curves could be obtained by subtraction of the responses for specific and control antibody-based sensors, thereby eliminating the effects of nonspecific adsorption of antigen. Sensors exposed to ciprofloxacin in milk gave increases in impedance whereas ciprofloxacin in phosphate buffer led to decreases, indicating the possibility of developing sensors which could both detect and differentiate between free and chelated antigen.

Similarly, the construction of an impedimetric immunosensor for the label-free detection of ciprofloxacin, was reported [76]. A poly(pyrrole-N-hydroxysuccinimide) film was electrogenerated onto electrodes and then used for the reagentless covalent binding of a fluoroquinolone model bearing an amino group. The resulting electrodes were utilized to immobilize a layer of anticiprofloxacin antibody onto the polymer surface by immunoreaction. In presence of ciprofloxacin, the antibody was displaced in solution inducing marked changes in the impedance of the sensor electrodes. These phenomena were detected and characterized by electrochemical impedance spectroscopy allowing the selective detection of extremely low ciprofloxacin concentration.

The high sensitivity that can be attained using an enzymatic system and mediated by catechol has been verified by on-line interfacing of a rotating biosensor and continuous-flow/stopped-flow/continuous-flow processing [77]. Horseradish peroxidase, HRP, immobilized on a rotating disk, in the presence of hydrogen peroxide catalyzed the oxidation of catechol, whose back electrochemical reduction was detected on glassy carbon electrode surface at $-200 \mathrm{mV}$. Thus, when ciprofloxacin or norfloxacin was added to the solution, these piperazine-containing compounds participate in Michael addition reactions with catechol to form the corresponding aminoquinone derivative, decreasing the peak current obtained in proportion with the increase of its concentration. Ciprofloxacin was used as the model piperazine-containing compound for the study. The influence of indicator composition on the nature of the analytical response has been assessed through examining the electrochemical properties of three derivatives. Interference by electroactive species (ascorbate, urate, and tyrosine) and other physiological constituents (cysteine, glutathione) has also been assessed.

The electrochemical behaviour of ofloxacin and some acidic and neutral pharmaceutical active compounds (clofibric acid, diclofenac and propranolol) was studied by cyclic voltammetry and pulse voltammetric techniques on mercury, carbon nanotube paste, carbon paste and gold electrodes [78]. The best results, in terms of sensitivity, linearity range and detection limits, were obtained by differential and normal pulse voltammetry. An enrichment step of approximately two orders of magnitude was performed by a solid-phase extraction procedure in order to concentrate the samples. The developed method was optimized and tested on spiked river water samples.

\section{INTERACTION OF QUINOLONES WITH DNA}

The mechanism of interaction between quinolones and DNA is not yet fully understood. Currently there is no definitive model for the interaction of quinolones with the DNA. 1H NMR studies were used to prove the existence of predominantly minor groove ciprofloxacin-duplex interactions, and to exclude classic intercalation between ciprofloxacin and DNA [79]. Other NMR studies suggested that norfloxacin exhibits both an intercalation-like interaction and non-specific groove binding to DNA [80-82]. Electric linear dichroism showed that norfloxacin is capable of interacting with DNA via both minor and major groove contacts [83]. However, another study using the same technique excluded the groove binding mode or surface binding of norfloxacin [84]. UV-melting curves and fluorescence emission spectra 
suggested that ciprofloxacin has at least two different binding modes; a non-specific binding to DNA molecules, which is electrostatically driven, and a specific nonelectrostatically controlled binding. The effect of ciprofloxacin on the change in intrinsic viscosity suggested that ciprofloxacin has the properties of an intercalative binder [85]. In recent years, there has been a growing interest in the electrochemical investigations of the interactions between quinolones drugs and DNA. Compared with other methods, electrochemical techniques are characterized by simplicity and require small amount of sample, thus offering advantages over commonly used assays (both biological and chemical). In this context, an effort is made to combine the outcome of electrochemical techniques with other reported methods in order to give a better understanding of the mode of interaction between quinolones and DNA. Electrochemical approach can also be used for the quantification of these drugs. Observing the electrochemical signal related to DNA-drug interactions can provide evidence for the interaction mechanism, the nature of the complex formed, binding constant, binding site size and the role of free radicals generated during interaction in the drug action. The mechanism of interaction between drugs and DNA can be explained electrochemically by two different ways; DNA-modified electrode and interaction in solution. Different types of working electrodes may be used such as, carbon paste electrode, glassy carbon electrode, gold electrode, hanging mercury drop electrode, pencil graphite electrode, screen-printed electrodes, carbon fiber column electrode and carbon fiber disk electrode. Different electrochemical techniques can be used for investigating drug-DNA interactions. The most common techniques are cyclic voltammetry, square wave voltammetry, and differential pulse voltammetry.

The electrochemical behavior of gatifloxacin and its interaction with natural calf thymus DNA (ctDNA) was investigated by differential pulse voltammetry on a carbon paraffined electrode [86]. According to the suggested electrochemical equation, binding constant and binding sizes of gatifloxacin with ctDNA was obtained by nonlinear fit analysis of electrochemical data. The results demonstrated that gatifloxacin has the properties of an intercalative binder.

Spectral and electrochemical studies have been carried out on the interaction of pefloxacin with calf thymus doublestranded dsDNA [87]. The voltammetric behavior of pefloxacin was investigated at glassy carbon, carbon paste and dsDNA-modified carbon paste electrodes using cyclic voltammetry. Pefloxacin was oxidized, yielding one irreversible oxidation peak. The modification of the carbon paste surface with dsDNA allowed an accumulation process to take place for pefloxacin such that higher sensitivity was achieved compared with the bare surface. The response was characterized with respect to ionic strength, accumulation time, pefloxacin concentration, and other variables. The stripping differential pulse voltammetry at the dsDNA modified electrode was applied to the direct determination of pefloxacin in diluted urine samples.

The electrochemical behavior of ciprofloxacin and its interaction with the natural calf thymus DNA (ctDNA) was explored by using pulse difference voltammetry on a carbon electrode [88]. Ciprofloxacin showed a well-defined oxidative peak as a result of reaction with ctDNA, the oxidative peak of ciprofloxacin decreased markedly. The binding constant and the binding size ciprofloxacin with ctDNA were obtained by nonlinear fit analysis of the electrochemical data according to the deduced electrochemical equation. The mechanism of the interaction was suggested.

Interactions between ciprofloxacin, $\mathrm{Mg}^{2+}, \mathrm{Mn}^{2+}$ and DNA, and their polarographic and voltammetric behaviour were studied in $\mathrm{NH}_{3}-\mathrm{NH}_{4} \mathrm{Cl}$ buffer solution [89], a new reduction peak was obtained by linear-sweep voltammetry when adding DNA to ciprofloxacin solution, which implies binding of ciprofloxacin with DNA. In the presence of $\mathrm{Mg}^{2+}$ or $\mathrm{Mn}^{2+}$, another new sensitive reduction peak, whose peak potential was more negative, was obtained which suggested that $\mathrm{Mg}^{2+}$ or $\mathrm{Mn}^{2+}$ took part in the interaction between ciprofloxacin and DNA resulting in a ternary complex of ciprofloxacin-Mg-DNA. Furthermore, ciprofloxacin-Mg was shown to be intercalated between the stacked base pairs of native DNA.

The voltammetric behavior of the lomefloxacin-Mg(II) complex with DNA at a mercury electrode was reported. In $\mathrm{NH}_{3}-\mathrm{NH}_{4} \mathrm{Cl}$ buffer, the adsorption phenomena of the lomefloxacin- $\mathrm{Mg}$ (II) complex were observed by linear sweep voltammetry [90]. The mechanism of the electrode reaction was found to be a reduction of lomefloxacin in the complex, and the composition of the lomefloxacin-Mg(II) complex is $2: 1$. In the presence of calf thymus DNA (ctDNA), the peak current of lomefloxacin-Mg(II) complex decreased considerably, and a new well-defined adsorptive reduction peak appeared. The electrochemical kinetic parameters and the binding number of lomefloxacin- $\mathrm{Mg}(\mathrm{II})$ with ctDNA were also obtained. Moreover, the new peak currents of lomefloxacin-Mg(II)-DNA system increased linearly correlated to the concentration of DNA. An electrostatic interaction was suggested by electrochemical method.

The interaction of ciprofloxacin with DNA was studied by using an electrochemical DNA biosensor [91]. The binding mechanism of ciprofloxacin was elucidated by using constant current potentiometry and differential pulse voltammetry at DNA-modified glassy carbon electrode. The decrease in the guanine oxidation peak area or peak current was used as an indicator for the interaction mechanism in 0.2 $\mathrm{M}$ acetate buffer. The binding constant values were obtained using constant current potentiometry and differential pulse voltammetry, respectively. A linear dependence of the guanine peak area or peak currents was observed with ciprofloxacin by using constant current potentiometry and differential pulse voltammetry, respectively. Moreover, the influence of sodium and calcium ions was also studied to elucidate the mechanism of ciprofloxacin-DNA interaction at different solution conditions, and this proved to be helpful in understanding the ciprofloxacin-DNA interaction.

The interaction of levofloxacin with double-stranded calf thymus DNA was studied in solution by cyclic voltammetry at glassy carbon electrode [92]. Voltammetric behavior of levofloxacin was also studied on dsDNA-modified electrodes. The binding of levofloxacin with DNA, immobilized onto the surface of an anodically activated carbon paste electrode, was exploited for designing a 
sensitive biosensor for levofloxacin. The response was optimized with respect to accumulation time, ionic strength, drug concentration, reproducibility and other variables. Direct and simple determination of levofloxacin in urine was established with no manipulation of urine sample other than dilution.

A glassy carbon electrode (GCE) modifying by nano-tin oxide/poly vinyl sulfonic potassium (nano- $\mathrm{SnO}_{2}$ ) exhibited an enhanced effectiveness for the oxidation of ciprofloxacin in phosphate buffer solutions, as compared with a bare GCE or a nano- $\mathrm{SnO}_{2}$ modified electrode [93]. In addition, the electrooxidation mechanism of the ciprofloxacin, ofloxacin, sparfloxacin and lomefloxacin at the modified electrode were also investigated. Furthermore, Gel electrophoresis coupled with electrochemistry and spectra techniques were used to study the interaction of ciprofloxacin and calf thymus DNA (ctDNA). The acquired data showed that the binding mode of ciprofloxacin and DNA was mainly an intercalation mechanism.

\section{CONCLUSIONS}

Given the power of stripping electroanalytical methods to detect a broad range of analytes at ultra-trace concentrations, its future is assured in areas where low-cost, portability and sensitivity are needed. This will include the detection of trace levels of pharmaceutically active compounds as well as biomedical screening applications. One possible route to improved performance is the miniaturisation of the electrodes by use of microelectrodes. The progress in design and production of optimized nanoparticle-modified electrodes may contribute to the development of simple electrochemical biosensors for studies of DNA interactions with a variety of substances, including drugs, mutagens, carcinogens, environmental pollutants, etc. Due to these properties, the electroanalytical methods may complement and eventually substitute some of the methods widely used in biochemical and molecular biological laboratories (such as gel electrophoresis, spectrophotometry, spectrofluorimetry etc).

\section{REFERENCES}

[1] Lesher, G.Y.; Froelich, E.J.; Gruett, M.D.; Bailey, J.H.; Brundage, R.P.J. 1,8-Naphthyridine derivatives. A new class of chemotherapeutic agents. Med. Pharm. Chem., 1962, 5, 1063.

[2] Hooper, D.C. Clinical applications of quinolones. Biochim. Biophys. Acta - Gene Struct. Express, 1998, 1400, 45.

[3] Bryan, L.E.; Bedard, J. Impermeability to quinolones in grampositive and gram-negative bacteria. Eur. J. Clin. Microbiol. Infect. Dis., 1991, 10, 232.

[4] Mroz, E.; Jankowski, S.; Bartelmus, J.; Grzybek-Hryncewicz, K.; Ruczkowska, J.; Starek, J.; Boratynska, M. Susceptibility to some quinolones of gram-negative bacteria and gram-positive cocci causing urinary tract infections. Med. Dosw. Mikrobiol., 1993, 45, 115 .

[5] Hooper, D.C. Quinolones. Principles and Practice of Infectious Diseases, $5^{\text {th }}$ ed. Churchill Livingstone: Philidelphia, PA, 2000, pp. 404-423.

[6] Oliphant, C.M.; Green, G.M. Quinolones: A comprehensive review. Am. Fam. Physician, 2002, 65, 455

[7] Drlica, K.; Hiasa, H.; Kerns, R.; Malik, M.; Mustaev, A.; Zhao, X. Curr. Top. Quinolones: Action and resistance updated. Med. Chem., 2009, 9, 981.

[8] Tovia A.F.; Ramirez V.A. Nalidixic acid. Therapeutic trial and antimicrobial activity in vitro. Preliminary study. Prensa. Med. Mex., 1963, 28, 47-53.

[9] Duggirala, A.; Joseph, J.; Sharma, S.; Nutheti, R.; Garg, P.; Das, T. Activity of newer fluoroquinolones against gram-positive and gram-negative bacteria isolated from ocular infections: An in vitro comparison. Indian J. Ophthalmol., 2007, 55, 15.

[10] King, D.E.; Malone, R.; Lilley, S.H. New classification and update on the quinolone antibiotics. Am. Fam. Physician, 2000, 61, 2741.

[11] Epstein, B.J.; Gums, J.G. Optimal pharmacological therapy for community-acquired pneumonia the role of dual antibacterial therapy. Drugs, 2005, 65, 1949 .

[12] Goff, D.A. Determining the cost of antimicrobial therapy: A focus on fluoroquinolones. Formulary, 1998, 33, 648 .

[13] Talan, D. A. New concepts in antimicrobial therapy for emergency department infections. Ann. Emerg. Med., 1999, 34, 503.

[14] Weiss, K.; Tillotson, G.S. The controversy of combination vs monotherapy in the treatment of hospitalized community-acquired pneumonia. Chest, 2005, 128, 940.

[15] Higgins, P.G.; Fluit, A.C.; Schmitz, F.J. Fluoroquinolones: Structure and target sites. Curr. Drug Targets, 2003, 4, 181

[16] Hooper, D.C. Mechanisms of action of antimicrobials: Focus on fluoroquinolones. Clin. Infect. Dis., 2001, 32(Suppl. 1), S9-S15.

[17] Hopkins, K.L.; Davies, R.H.; Threlfall, E.J. Mechanisms of quinolone resistance in Escherichia coli and Salmonella: Recent developments. Int. J. Antimicro. Ag., 2005, 25, 358.

[18] Jacobs, M.R. Fluoroquinolones as chemotherapeutics against mycobacterial infections. Curr. Pharm. Des., 2004, 10, 3213.

[19] Keam, S.J.; Croom, K.F.; Keating, G.M. Gatifloxacin: A review of its use in the treatment of bacterial infections in the US. Drugs, 2005, 65, 695 .

[20] Luzzaro, F. Fluoroquinolones and Gram-negative bacteria: Antimicrobial activity and mechanisms of resistance. Fluorochinoloni e Gram-negativi: Differenze di attività e nuove evidenze sui meccanismi di resistenza. 2008, 16 (Suppl. 2), 5-11.

[21] Schmitz, F.J.; Higgins, P.; Mayer, S.; Fluit, A.; Dalhoff, A. Activity of quinolones against gram-positive cocci: Mechanisms of drug action and bacterial resistance. Eur. J. Clin. Microbiol. Infect. Dis., 2002, 21, 647.

[22] Tzeng, C.C.; Chen, Y.L. Recent developments in antibacterial 4quinolone-3-carboxylic acids. Chin. Pharm. J., 2002, 54, 229.

[23] Hooper, D.C.; Wolfson, J.S. Mechanisms of quinolone action and bacterial killing. In: Quinolone Antimicrobial Agents, $2^{\text {nd }}$ ed. Washington, D.C., American Society of Biology, 1993, pp. 53-75.

[24] Tornaletti, S.; Pedrini, A.M. Studies on the interaction of 4quinolones with DNA by DNA unwinding experiments. Biochim. Biophys. Acta - Gene Struct. Express, 1988, 949, 279.

[25] Gmunder, H.; Kuratli, K.; Keck, W. Effect of pyrimido[1,6a]benzimidazoles, quinolones, and $\mathrm{Ca} 2+$ on the DNA gyrasemediated cleavage reaction. Antimicrob. Agents Chemother., 1995, $39,163$.

[26] Sissi, C.; Andreolli, M.; Cecchetti, V.; Fravolini, A.; Gatto, B.; Palumbo, M. $\mathrm{Mg}^{2+}$-mediated binding of 6-Substituted quinolones to DNA: Relevance to biological activity. Bioorg. Med. Chem., 1998, 6, 1555 .

[27] Marchetto, R.; Nicolás, E.; Castillo, N.; Bacardit, J.; Navia, M.; Vila, J.; Giralt, E. J. Two short peptides including segments of subunit A of Escherichia coli DNA gyrase as potential probes to evaluate the antibacterial activity of quinolones. Peptide Sci., 2001, 7,27

[28] Pan, X.S.; Gould, K.A.; Fisher, L.M. Probing the differential interactions of quinazolinedione PD 0305970 and quinolones with gyrase and topoisomerase IV. Antimicrob. Agents Chemother., 2009, 53, 3822.

[29] Belal, F.; Al-Majed, A.A.; Al-Obaid, A.M. Methods of analysis of 4-quinolone antibacterials. Talanta, 1999, 5, 765.

[30] Radi, A.E. Applications of stripping voltammetry at carbon paste and chemically modified carbon paste electrodes to pharmaceutical analysis. Curr. Pharm. Anal., 2006, 2, 1.

[31] Ozkan, S.A. Principles and techniques of electroanalytical stripping methods for pharmaceutically active compounds in dosage forms and biological samples. Curr. Pharm. Anal., 2009, 5, 127.

[32] Uslu, B.; Ozkan, S.A. Solid electrodes in electroanalytical chemistry: Present applications and prospects for high throughput screening of drug compounds. Comb. Chem. High Throughput Screen., 2007, 10, 495.

[33] Staroscik, R.; Prochowska, I.; Sulkowska, J. Polarography of nalidixic acid. Pharmazie, 1974, 29, 387.

[34] Van Oort, W.J.; Sorel, R.H.A.; Brussee, D. Polarographic reduction and determination of nalidixic acid. Anal. Chim. Acta., 1983, 149, 175 . 
[35] Ibrahim, M.S.; Shehatta, I.S.; Sultan, M.R. Cathodic adsorptive stripping voltammetric determination of nalidixic acid in pharmaceuticals. Talanta, 2002, 56, 471.

[36] Cabanillas, A.G.; Cáceres, M.I.R.; Cañas, M.A.M.; Burguillos, J.M.O.; Díaz, T.G. Square wave adsorptive stripping voltametric determination of the mixture of nalidixic acid and its main metabolite (7-hydroxymethylnalidixic acid) by multivariate methods and artificial neural network. Talanta, 2007, 72, 932.

[37] Rizk, M.; Belal, F.; Aly, F.A.; El-Enany, N.M. Differential pulse polarographic determination of ofloxacin in pharmaceuticals and biological fluids. Talanta, 1998, 46, 83 .

[38] Zhou, G.R.; Fan, H.Z.; Pan, J.H. Polarographic and voltammetric behaviour of enoxacin. Analyst, 1995, 120, 2237.

[39] Belal, F.; El-Din, M.S. Polarographic behavior and determination of Flumequine. Microchem. J., 1990, 42, 300.

[40] Warowna-Grześkiewicz, M.; Chodkowski, J.; Fijałek, Z. Electrochemical studies of some quinolone antibiotics. Part III. Determination by linear sweep voltammetry in substance and in pharmaceutical formulations. Acta Pol. Pharm. Drug Res., 1996, 53,241 .

[41] Warowna-Grześkiewicz, M.; Chodkowski, J.; Fijałek, Z. Electrochemical studies of some quinolone antibiotics. Part II. Determination by differential pulse polarography in substance and in pharmaceutical formulations. Acta Pol. Pharm., 1995, 52, 441 .

[42] Solangi, A.R.; Mallah, A.; Khuhawar, M.Y.; Bhanger, M.I. Cathodic stripping voltammetry of pipemidic acid and ofloxacin in pharmaceutical dosages and human urine. J. Iran. Chem. Soc., 2009, 6, 71

[43] Ni, Y.; Wang, Y.; Kokot, S. Simultaneous determination of three fluoroquinolones by linear sweep stripping voltammetry with the aid of chemometrics. Talanta, 2006, 69, 216.

[44] Warowna-Grześkiewicz, M.; Chodkowski, J.; Fijałek, Z. Electrochemical studies of some quinolone antibiotics. Part I. Qualitative analysis on mercury and carbon electrodes. Acta Pol. Pharm., 1995, 52, 187.

[45] Li, Q.L.; Cao, X.L.; Hu, J.B. Studies on the adsorptive behaviour of norfloxacin and its determination. Yaохиe Xuebao, 1996, 31, 287.

[46] Jaber, A.M.Y.; Lounici, A. Adsorptive differential-pulse stripping voltammetry of norfloxacin and its analytical application. Analyst, 1994, 119, 2351

[47] Wang, X. L.; Zhang, S. M.; He, C. X. A study on single-sweep oscillopolarography of ciprofloxacin lactate. Chem. J. Chin Univ., 1996, 17, X10.

[48] Beltagi, A.M. Determination of the antibiotic drug pefloxacin in bulk form, tablets and human serum using square wave cathodic adsorptive stripping voltammetry. J. Pharm. Biomed. Anal., 2003, 31,1079 .

[49] Rizk, M.; Belal, F.; Ibrahim, F.; Ahmed, S.; El-Enany, N.M. Voltammetric analysis of certain 4-quinolones in pharmaceuticals and biological fluids. J. Pharm. Biomed. Anal., 2000, 24, 211.

[50] Trindade, M.A.G.; Da Silva, G.M.; Souza Ferreira, V. Determination of moxifloxacin in tablets and human urine by square-wave adsorptive voltammetry. Microchem. J., 2005, 81, 209.

[51] Inam, R.; Mercan, H.; Yilmaz, E.; Uslu, B. Differential pulse polarographic determination of moxifloxacin hydrochloride in pharmaceuticals and biological fluids. Anal. Lett., 2007, 40, 529.

[52] Kapetanović, V.; Milovanović, L.; Aleksić, M.; Ignjatović, L. Voltammetric methods for analytical determination of fleroxacin in Quinodis ${ }^{\circledR}$ tablets. J. Pharm. Biomed. Anal., 2000, 22, 925.

[53] Nanda, N.; Tanu, M.; Mayanna, S.M. Cyclic voltammetric study of biologically active metal ions with norfloxacin. Indian J. Chem. Technol., 1999, 6, 325.

[54] Jain, S.; Jain, N.K.; Pitre, K.S. Bio-inorganic studies on the Fe(II) sparfloxacin complex. Met. Based Drugs, 2002, 9, 1.

[55] Abdel Ghani, N.T.; El-Ries, M.A.; El-Shall, M.A. Validated polarographic methods for the determination of certain antibacterial drugs. Anal. Sci., 2007, 23, 1053.

[56] Trindade, M.A.G.; Cunha, P.A.C.; De Araújo, T.A.; Da Silva, G.M.; Ferreira, V.S. Interaction study of moxifloxacin with $\mathrm{Cu}(\mathrm{II})$ ion using square-wave voltammetry and its application in the determination in tablets. Eclética Quím., 2006, 31, 31.

[57] Inam, R.; Mercan, H.; Yilmaz, E.; Uslu, B. Differential pulse polarographic determination of $\mathrm{Co}(\mathrm{II})$ using moxifloxacine. $J$. Anal. Chem., 2007, 62, 592.
[58] Gholivand, M.B.; Pourhossein, A.; Shahlaei, M. Application of adsorptive cathodic stripping voltammetry for determination of trace amounts of zinc using nalidixic acid as a chelating agent. Chem. Anal., 2009, 54, 655.

[59] Ensaifi, A.A.; Khayamian, T.; Taei, M. Determination of ultra trace amount of enrofloxacin by adsorptive cathodic stripping voltammetry using copper(II) as an intermediate. Talanta, 2009, 78,942 .

[60] He, Y.N.; Chen, H.Y. Differential pulse adsorptive anodic stripping voltammetric determination of pipemidic acid in tablets at a carbon fiber microdisk electrode. Electroanalysis, 1997, 9, 1426.

[61] Girish Kumar, K.; Augustine, P.; Poduval, R.; John, S. Voltammetric studies of sparfloxacin and application to its determination in pharmaceuticals. Pharmazie, 2006, 61, 291.

[62] Ghoneim, M.M.; Radi, A.; Beltagi, A.M. Determination of Norfloxacin by square-wave adsorptive voltammetry on a glassy carbon electrode. J. Pharm. Biomed. Anal., 2001, 25, 205.

[63] Hanwen, S.; Tao, X.; Kaoqi, L.; Shuxuan, L. Determination of norfloxacin using an electrochemically pretreated glassy carbon electrode. Chem. J. Internet, 2006, 8, 088054pe.

[64] Uslu, B.; Topal, B.D.; Ozkan, S.A. Electroanalytical investigation and determination of pefloxacin in pharmaceuticals and serum at boron-doped diamond and glassy carbon electrodes. Talanta, 2008, 74,1191

[65] Yi, H.; Li, C. Voltammetric determination of ciprofloxacin based on the enhancement effect of cetyltrimethylammonium bromide (CTAB) at carbon paste electrode. Russ. J. Electrochem., 2007, 43, 1377.

[66] Radi, A.; El-Sherif, Z. Determination of levofloxacin in human urine by adsorptive square-wave anodic stripping voltammetry on a glassy carbon electrode. Talanta, 2002, 58, 319 .

[67] Komorsky-Lovrić, S.; Nigović, B. Identification of 5aminosalicylic acid, ciprofloxacin and azithromycin by abrasive stripping voltammetry. J. Pharm. Biomed. Anal., 2004, 36, 81.

[68] El Ries, M.A.; Wassel, A.A.; Abdel Ghani, N.T.; El-Shall, M.A. Electrochemical adsorptive behavior of some fluoroquinolones at carbon paste electrode. Anal. Sci., 2005, 21, 1249.

[69] Erk, N. Voltammetric behaviour and determination of moxifloxacin in pharmaceutical products and human plasma. Anal. Bioanal. Chem., 2004, 378, 1351

[70] Madhusudana, R.T.; Balaji, K.; Jayarama, R.S. Voltammetric behavior of some fluorinated quinolone antibacterial agents and their differential pulse voltammetric determination in drug formulations and urine samples using a $\beta$-cyclodextrin-modified carbon-paste electrode. J. Anal. Chem., 2007, 62, 168.

[71] Reddy, T.M.; Sreedhar, M.; Reddy, S.J. Electrochemical determination of sparfloxacin in pharmaceutical formulations and urine samples using a $\beta$-cyclodextrin modified carbon paste electrode. Anal. Lett., 2003, 36, 1365.

[72] Huang, K.J.; Liu, X.; Xie, W.Z.; Yuan, H.X. Electrochemical behavior and voltammetric determination of norfloxacin at glassy carbon electrode modified with multi walled carbon nanotubes/Nafion. Colloids Surf., B, 2008, 64, 269.

[73] Huang, K. J.; Xu, C.X.; Xie, W.Z. Electrochemical behavior of norfloxacin and its determination at poly(methyl red) film coated glassy carbon electrode. Bull. Korean Chem. Soc., 2008, 29, 988.

[74] Chi, Y.; Li, J. Determination of levofloxacin hydrochloride with multiwalled carbon nanotubes-polymeric alizarin film modified electrode. Russ. J. Electrochem., 2010, 46, 155.

[75] Tsekenis, G.; Garifallou, G.Z.; Davis, F.; Millner, P.A.; Pinacho, D.G.; Sanchez-Baeza, F.; Marco, M.P.; Gibson, T.D.; Higson, S.P.J. Detection of fluoroquinolone antibiotics in milk via a labeless immunoassay based upon an alternating current impedance protocol. Anal. Chem., 2008, 80, 9233.

[76] Giroud, F.; Gorgy, K.; Gondran, C.; Cosnier, S.; Pinacho, D.G.; Marco, M.P.; Sánchez-Baeza, F.J. Impedimetric immunosenso based on a polypyrrole-antibiotic model film for the label-free picomolar detection of ciprofloxacin. Anal. Chem., 2009, 81, 8405 .

[77] Torriero, A.A.J.; Salinas, E.; Raba, J.; Silber, J.J. Sensitive determination of ciprofloxacin and norfloxacin in biological fluids using an enzymatic rotating biosensor. Biosens. Bioelectron., 2006 $22,109$.

[78] Ambrosi, A.; Antiochia, R.; Campanella, L.; Dragone, R.; Lavagnini, I. Electrochemical determination of pharmaceuticals in spiked water samples. J. Hazard. Mater., 2005, 122, 219. 
[79] Moulopoulos, K.; Constantinou, M. Interaction between ciprofloxacin and DNA mediated by $\mathrm{Mg}^{+2}$-ions Inorg. Chim. Acta, 2002, 339, 239

[80] Evstigneev, M.P.; Baranovskiǐ, S.F.; Rybakova, K.A.; Davis, D.B. $1 \mathrm{H}$ NMR study of the complexation of the quinolone antibiotic norfloxacin with DNA. Mol. Biol., 2006, 40, 894.

[81] Evstigneev, M.P.; Baranovsky, S.F.; Rybakova, K.A.; Davies, D.B. Complexation of the quinolone antibiotic norfloxacin with DNA. Mol. Biol., 2006, 40, 805 .

[82] Sandström, K.; Wärmländer, S.; Leijon, M.; Gräslund, A. ${ }^{1}$ H NMR studies of selective interactions of norfloxacin with doublestranded DNA. Biochem. Biophys. Res. Commun., 2003, 304, 55.

[83] Bailly, C.; Colson, P.; Houssier, C. The orientation of norfloxacin bound to double-stranded DNA. Biochem. Biophys. Res. Commun., 1998, $243,844$.

[84] Son, G.S.; Yeo, J.A.; Kim, M.S.; Kim, S.K.; Holmén, A.; Åkerman, B.; Nordén, B. Binding mode of norfloxacin to calf thymus DNA. J. Am. Chem. Soc., 1998, 120, 6451.

[85] Vilfan, I.D.; Drevenšek, P.; Turel, I.; Poklar Ulrih, N. Characterization of ciprofloxacin binding to the linear single- and double-stranded DNA. Biochim. Biophys. Acta - Gene Struct. Express., 2003, 1628, 111.
[86] Guo, M.; Yu, Q.S. Electrochemical characteristics of gatifloxacin and its interaction with DNA. Anal. Sci., 2006, 22, 685.

[87] Radi, A.; El Ries, M.A.; Kandil, S. Spectroscopic and voltammetric studies of Pefloxacin bound to calf thymus double-stranded DNA. Anal. Bioanal. Chem., 2005, 381, 451 .

[88] Shi, Q.; Wang, S.; Zhu, B.; Ji, M. Electrochemical studies of reaction of ciprofloxcin and DNA. Front. Chem. Chin., 2008, 3, 52.

[89] Zhang, J.L.; Fan, H.Z.; Pan, J.H. Interactions between ciprofloxacin, $\mathrm{Mg}^{2+}, \mathrm{Mn}^{2+}$ and $\mathrm{DNA}$ by electrochemical method. Yaoxue Xuebao, 1997, 32, 314.

[90] Zhang, N.; Zhang, X.; Zhao, Y. Voltammetric study of the interaction of lomefloxacin (LMF)-Mg(II) complex with DNA and its analytical application. Microchem. J., 2003, 75, 249.

[91] Nawaz, H.; Rauf, S.; Akhtar, K.; Khalid, A.M. Electrochemical DNA biosensor for the study of ciprofloxacin-DNA interaction. Anal. Biochem., 2006, 354, 28.

[92] Radi, A.; El Ries, M.A.; Kandil, S. Electrochemical study of the interaction of levofloxacin with DNA. Anal. Chim. Acta, 2003, 495, 61.

[93] Cai, Y.; Zhang, Y.; Su, S.; Li, S.; Ni, Y. Electrochemical studies oxidation of ciprofloxacin at nano- $\mathrm{SnO}_{2} / \mathrm{PVS}$ modified electrode and its interaction with calf thymus DNA. Front. Biosci., 2007, 12, 1946.

(c) Abd-Elgawad Radi; Licensee Bentham Open.

This is an open access article licensed under the terms of the Creative Commons Attribution Non-Commercial License (http://creativecommons.org/licenses/by$\mathrm{nc} / 3.0 /$ ) which permits unrestricted, non-commercial use, distribution and reproduction in any medium, provided the work is properly cited. 